\title{
Personalized learning with digital technologies at home and school: where is children's agency?
}

Natalia Kucirkova, UCL Institute of Education

\section{Introduction}

Most primary school teachers know that effective education needs to be personalised to individual children and at the same time, connected to the wider socio-cultural community in which children grow up. When educational researchers study this complex process of effective pedagogies, they need to analyse the intersection between individualised approaches and community-oriented approaches to learning. Such an approach is described as a fine balancing act between individualisation and standardisation (Garrick, Pendergast \& Geelan, 2017) or what we termed personalised pluralisation (Kucirkova \& Littleton, 2017). In Kucirkova \& Littleton (2017), we argued that personalised pluralisation is the most effective model for deploying mobile technologies in UK primary schools, but the model's application needs to be context-sensitive.

In this chapter, I focus on the context of one classroom in a primary school in the UK to outline what personalised learning might look like; that is, what learning opportunities it might engender and what pedagogical practices it might entail. I build on some empirical observations from six ten-year-old children's interactions with technologies in the classroom, and their accounts of technology experiences at home, to explore the notion of agency in personalised learning. The ultimate aim of this chapter is to share some innovative practices and guide an effective deployment of digital technologies that would honour children's agency and connect their home and school learning experiences.

\section{Digital technologies: key considerations}

Technologies have always been an integral part of classrooms, but while their purpose of use has little changed over the years, their forms have changed significantly. For example, the purpose of using a ballpoint pen or an iPad pen stylus is the same: to capture a verbal or mental thought. However, the final product and the process leading to its development are in the $21^{\text {st }}$ century by and large digital. Many educational researchers therefore make the distinction between old and new technologies or digital and non-digital technologies. For instance, Mercer, Hennessy and Warwick (2010) describe how interactive whiteboards (digital technologies) relate to flipcharts and dry-wipe boards (non-digital technologies) but fulfil the same aim of collaborative learning.

There are some common factors that influence children's learning, and these factors interact with personalised and pluralised educational approaches. Even though children's use of technology is often studied in terms of access to technology or the technology's availability in a given setting, educationalists need to study more nuanced issues concerning the actual use of technologies, not just whether children own or access them . A useful way of framing these considerations is to think about the various "Cs" of technology use. The Cs relate to the content, context and individual child (Guernsey, 2012), or what Blum-Ross and Livingstone 
(2016, p.4) described as focus on the 'screen context (where, when and how digital media are accessed), content (what is being watched or used), and connections (whether and how relationships are facilitated or impeded)'. I have argued (see Kucirkova, 2015) that the Cs of children's technology use (context, content, individual child and their combinations or compounds) are conveniently related to another set of Cs, namely the Cs in children's skills, as listed by Hirsh-Pasek and Golinkoff (2016): critical thinking, creative innovation, collaboration, communication and content. The Cs are thus a simple but powerful frame to consider the added value of technologies to children's learning.

The first C- context- encourages us to consider the influence of a specific context on the usefulness of a given technology. For example, in developing countries, where there is often lack of basic sanitation and safe water, it seems to be a misguided attempt to send iPads to schools. Yet, the techno-driven (rather than vision-driven) agenda behind many technologydonating projects, such as for example One Laptop per Child, seems to be little informed by the local context (e.g., Kraemer, Dedrick, \& Sharma, 2009).

The second C-content- reminds us that the usefulness of a technology very much depends on the content delivered or enabled by this technology. There needs to be a match between the content and the task at hand. Even if two children sit in the same classroom with the same tablet in their hands, they could be having very different learning experiences. For example, one child might be playing Minecraft, while the other child might be watching inappropriate YouTube cartoons.

The third $\mathrm{C}$ is a reminder of the influence of individual characteristics of children, including their needs, talents and preferences. Despite this seemingly obvious fact, young children's use of technologies is often associated with the popular rhetoric of "digital natives" (Prensky, 2001). The term "digital natives" implies that children are one homogeneous group and are born into the world knowing how technology works. However, as I have discussed at length (Kucirkova, 2018), even though many children, especially those born in Western countries, grow up in environments that are saturated with technologies, the children are not born as digitally proficient. Any assumption of homogeneity among young children need balancing and in the case of the digital natives, it is important to recognise and research the complex circumstances in which individual children interact with technologies.

In this chapter, and in my work more generally, I aim to identify and explain the nuances and complexities in children's use of technology in relation to personalised pluralisation and the many "Cs" of technologies related to children's learning. This approach necessitates time and space for discussion, so I limit myself to a specific argument in this chapter. I consider the pedagogy and practices within a specific context (a Year 6 classroom in an English primary school), with a particular type of technology (mobile technologies) and a specific type of learning and pedagogical approach (personalised learning). Before I outline the context of the study in more detail, I define what I mean by mobile technologies and personalised learning.

\section{What are mobile technologies?}


As the name reveals, mobile technologies are mobile; that is, they can be transported from one location to another one. The mobility is facilitated with their light weight, a long battery life and suitable size. Mobile technologies have been on the market throughout the $21^{\text {st }}$ century in the form of netbooks and laptops, but it wasn't until early 2010s that tablets, iPads, smartphones and iPhones began to replace older mobile devices. In this chapter I focus on this second generation of mobile technologies, often subsumed under the umbrella term of digital or new technologies. iPads and tablets are particularly popular among pre- and primary school-aged children (Ofcom, 2015; 2016), with thousands of software programs (apps) developed for this age group (Vaala, Ly \& Levine, 2015). The quality of apps is variable, with many self-proclaimed educational apps not meeting researcher-developed quality criteria (see Papadikis, Kalogiannakis, \& Zaranis, 2018). This chapter doesn't focus on any particular apps, but on a particular way in which apps might be used in the classroom. It focuses on personalised learning, to complement the multiple uses of mobile technologies among young children discussed in this book.

\section{What is personalised learning?}

Personalised learning is a key theme in innovative educational approaches (Sharples et al., 2015) and it is also one of the five key ways in which mobile technologies have been claimed to transform education (Traxler, 2011). There are several practices that can be subsumed under personalised education. For instance, the 2015 'Innovating Pedagogy' report details five 'personalisation' themes that have emerged over the last four years: personal inquiry learning, dynamic assessment, adaptive teaching, analytics of emotions and stealth assessment (Sharples et al., 2015). In higher education, personalised learning relates to selfpaced and self-selected learning paths that students can choose from (Garrick, Pendergast, \& Geelan, 2017). Whether these learning paths are truly personalized or simply the same content offered to learners in a different sequence (a question raised by Neil Selwyn, 2016, in his book 'Is Technology Good for Education?'), is to be debated. What is clear is that the prevalence of personalised learning opportunities has risen with the advent of mobile technologies.

Educators use mobile technologies in a variety of ways, for example to document and evaluate children's progress with multimedia (video, audio and picture-based) evidence of activities or to enhance their existing activities with additional resources (for example by using a counting app to enrich a Maths lesson). Mobile technologies are, with their small screen, portability and user-friendly interface, designed for individual use and offer apps that can be used to personalise the learning experience. In addition, personal mobile technologies come with algorithms that are capable of measuring students' engagement with particular content and tailor subsequent content based on the students' performance. These characteristics mean that mobile technologies can be used for learning analytics, which is a particularly popular aspect of personalised learning in the $21^{\text {st }}$ century.

More specifically, learning analytics can model learner characteristics and provide subsequent recommendations, as if they were the students' personal tutor (Johnson, Adams Becker, Estrada, \& Freeman, 2015). With increasingly more children to teach and fewer 
graduates interested in the teaching profession in Europe and the UK (see e.g., Bélanger \& Broeks, 2016), learning analytics are becoming integrated in many educational institutions worldwide. Learning analytics are also a key component of new textbooks developed to motivate students to learn, such as for example the McGraw Hill's LearnSmart system, that allows teachers to tailor digital textbooks according to individual students or classrooms they teach in.

Thus, personalised learning can take many forms, some of which are determined by the child/learner and some of which are provided by the adult to the child. In considering these different forms it is useful to ask whether personalised education is offered as a programmatic/prescriptive or participatory approach.

\section{Programmatic versus participatory personalised learning}

The participation/prescription axes allow for bringing together the "Cs" of technology use and its learning impact and thus weave in the perennial questions of media use. Programmatic personalised learning occurs when learners are provided with personalised content automatically, with little agency and choice given to the learners. For example, personalised books are personalised according to a reader's preferences and characteristics (e.g., in the Lost My Name book by Wonderbly, the main story character in a book carries the child's name). Personalised reading systems are often based on programmatic, dynamic and ondemand personalization (e.g., the iRead by UCL Knowledge Lab ecosystem of personalised reading apps provides children with reading content relevant for their reading level). These products are personalised based on children's data that are either collected automatically or supplied by the children's carers to the providers.

At the other end of the spectrum lies participatory personalised learning where learners can participate in the design of education tailored to their own needs and preferences. An example of participatory personalised learning is the study by Van Dijk and colleagues with Dutch children in a science museum. van Dijk, Lingnau and Kockelkorn (2012) asked a group of children to use a tabletop to select the exhibition areas they liked most. Children were divided into two groups and were asked to select the content on their own. In one group, the children were given the option to follow their own (personalised) route through the museum and in the second group, the children followed a route that didn't contain their favourite objects. Although the children in the two different groups did not notice a difference, there was a difference in their understanding measured at the end of the activity. The children who could choose their preferred subjects scored higher on the tests evaluating their understanding. Given the design of the study, van Dijk and colleagues argue that this was because children in this group had greater interest in the topics encountered during the tour. The study thus provides tentative results for concluding that when children are given the choice and can individualise their learning path, it can have a positive learning effect.

I am interested in participatory personalised learning that honours the child's own choices and that considers children's agency. To understand how agency relates to personalised learning and how it differs from related terms, such as autonomy or volition, I use the 5As of 
personalisation framework. This framework was developed in my previous work (Kucirkova, 2017), in which I reviewed a broad range of literature on personalised reading. It consists of five dimensions or research variables/psychological phenomena: attachment, autonomy, authorship, authenticity and aesthetics. The 5As are all related to each other and can be represented as a set of five interlinked Venn diagrams. The autonomy and aesthetic dimensions are most closely related to agency in the context of using mobile technologies for digital reading (Kucirkova \& Gattis, in preparation). In this chapter I focus the attention on agency as a core variable in children's personalised learning with mobile technologies.

Figure 1: The "5As" of personalisation: five variables with agency at the core

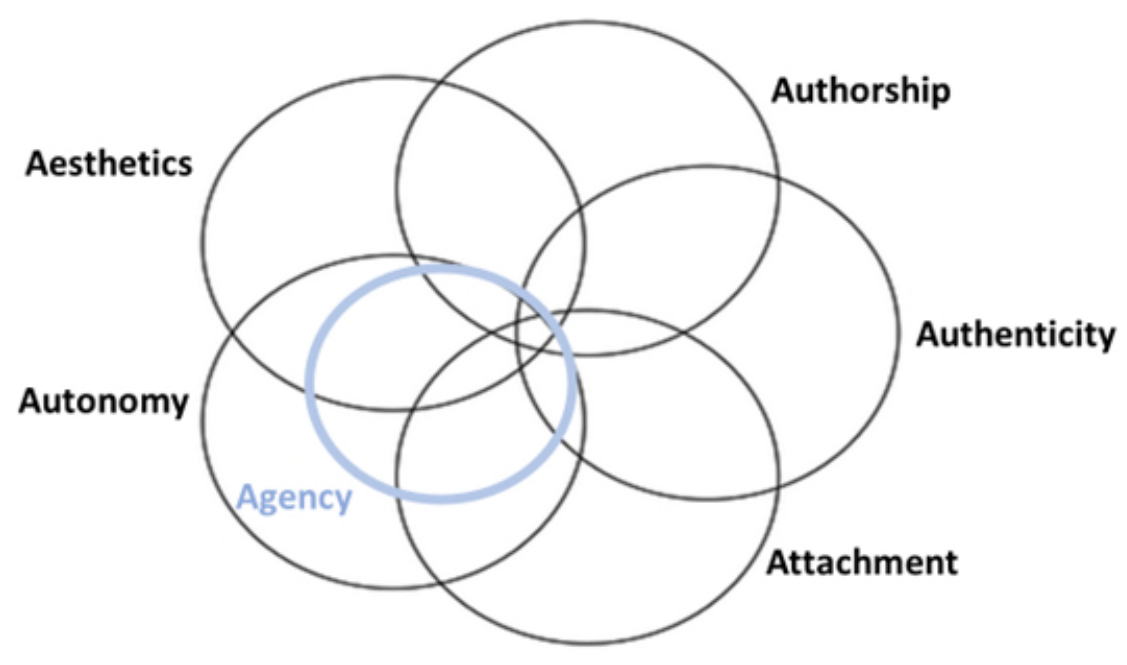

\section{Children's agency in personalised learning}

Broadly speaking, children's agency refers to the extent to which children's engagement is determined by them rather than anyone else. Supporting children's agency is a key rationale and justification for adopting personalised education as opposed to standardised education. There are different definitions of agency depending on the disciplinary perspective adopted. Agency is defined differently in business administration and economics (Kunz \& Pfaff, 2002) than in sociology, for example (Shapiro, 2005). In the sociology literature, agency has been conceptualised in terms of socially just pedagogies and learner agency facilitated by adults (e.g., Lupton \& Hempel-Jorgensen, 2012). Hempel-Jorgensen (2015, p.6) alludes to the transformative learning power of children's agency in the context of socially just pedagogies. For learning to occur, children need to be given opportunities to question, analyse, and reimagine their own learning environments. In specific activities such as for example book reading, agency has been defined as a 'compulsive reiterative role-playing in which individuals attempt to find themselves by going outside the self' (Travis, 1998, p.6). In the NP3 project, from which I draw in this chapter, agency was defined as 'evidence of choice or involvement in decision making' (Twining et al., 2017, p. 49). In the project, agency was 
considered as a key component of an innovative pedagogy framework, in which active knowledge construction was characterised by learners' agentive engagement with technologies in their immediate and wider socio-cultural environment.

\section{Adults' mediation of children's technology: classroom and home}

Children's agency can be constrained or enhanced by the adults around them. From a broader theoretical perspective, adults' mediation of agency and children's technology use relates to their rights and democracy principles. Applying Bernstein's framework for 'conditions for democracy', Leaton-Gray (2017) discusses the so-far little explored relationship between technology and time in education. She outlines how time and access to technology can provide deep insights into the nature of children's learning with technologies. Notably, she makes a distinction between personal and social agency and argues that access to resources is only one way of understanding actual technology use and children's personal agency. Drawing on Bernstein's pedagogic rights framework, Leaton-Gray argues: 'Even if routine and reliable access to high-level technology is technically possible, it may be that some groups of pupils are unable to afford it or do not wish to engage with it for their own reasons. Under such conditions it is not enough to see the role of educational technology relating exclusively to issues of individual agency. This represents a wider problem to do with the fair and effective distribution of resources across society, including within areas and amongst groups where it is not financially profitable for businesses to invest substantial resources (...).' (p.67).

There is a rich set of literature on how parents' attitudes towards technology influence children's use of technologies at home (Kucirkova \& Littleton, 2016) but also children's understanding of what technology is for. For example, Eisen and Lillard (2017) examined in an experimental design whether children see the functionality and purpose of touchscreen devices differently from traditional media like televisions and computers. They showed children photographs of a book, an iPad, a flat screen television (TV), an iPhone, a PC laptop computer, and a wireless home telephone and asked them to comment on their functionalities. The researchers found that parents' perceptions can influence children's understanding of technology functionalities. For the fourteen 4-year-olds, fourteen 5-year-olds and fifteen 6year-olds, who took part in their study, touchscreens were perceived to be for play while computers for work. There was a significant age difference, with older children recognising multifunctionality of mobile devices more than the young children whose experiences are informed more by home than school use. In Gillen and Kucirkova (forthcoming), we discuss how the home-school difference in using technologies might influence children's perceptions.

This chapter aims to contribute to this body of work and answer a set of questions related to personalised learning with a focus on children's agency. I ask, first more broadly: How do teachers make use of mobile technologies in the school? The second and third research questions are more specific: What does agency look like in the context of a primary school classroom where children use mobile technologies? What are children's experiences and perceptions of the ways mobile technologies have had an impact on their agency? 


\section{Methods}

\section{Study context: the NP3 project}

The data discussed in this chapter are part of the New Purposes - New Practices - New Pedagogy Project, NP3 Project for short. The NP3 project was funded by the Society for Educational Sciences in the UK and was led by Professor Peter Twining in 2015-2017, together with colleagues from the Open University and Lancaster University. The project aimed to explore the digital practices that children engage with outside school and the extent to which these are recognised and valued inside the school settings they attend. The main concern of the research project was to establish the institutional factors that impact on schools' responses to pupils' digital competences and digital practices outside school. The project involved intense data collection in thirteen schools across the UK, with over 100 children and more than 60 teachers participating in the study. A number of publications and reports resulted from the project, all of which are available on the project website:

http://www.np3.org.uk. In this chapter I focus on data that I collected while working as a consultant on this project. The data were all collected in one school and I only focus on one classroom to maintain the integrity of the argument.

\section{The school}

This school, called Northgate Primary for anonymisation purposes, is a small Community Foundation school, in an urban/suburban area of Northern England. The school is smaller than the average-sized primary school in the UK, with 189 children attending the school overall. The majority of children are White British, although there are some children with English as a Second Language. The school caters for children from nursery to Year 6; that is, children aged between three to eleven years. The school has a higher than average number of children on Free School Meals (measure of socio-economic deprivation in the UK) and with Special Educational Needs. A small proportion of children come from relatively affluent households. The school uses national research from major funding agencies to inform their strategic decisions and has received a number of prestigious awards, recognising the school's innovative practices in the area of art, engagement with local community and use of technologies.

I visited the school in autumn 2016 and in this chapter summarise findings based on overall eight days of observations of classroom practice and interviews with six 'log children' in the Year6 classroom.

\section{Study participants}

There were 43 "log children" in the NP3 project, who were selected by their teachers to provide additional evidence of how the children engage with technologies at home. The researchers collected more detailed information about these children and the log children were also provided with digital cameras and encouraged to take pictures of any technology they have at home. At the school visit, the researcher interviewed each log child and asked $\mathrm{him} /$ her to describe what the pictures represented. In the Northgate school, six log children were interviewed. The children were aged between ten to eleven years and there were two girls and four boys in the group. I draw on the transcribed interview data with these children to present evidence on children's use of technologies at home. 


\section{Data collection and analysis}

During my visits to the Northgate school I took video recordings of all observed lessons as well as audio recordings of interviewed teachers, school senior leadership team and the six $\log$ children. I took field notes to capture moments that may have not been captured digitally. I also took several still photographs to describe the specific technologies children used or the physical layout of the classrooms and artefacts produced by the children. The audio and video data were entered into the Maxqda data analysis tool and transcribed by the research team. For the analytical purposes in this chapter I only focus on the fieldnotes, video and audio transcripts salient for personalised learning. I analysed these data thematically; that is, I collated similar examples of audio/video and observational data that clustered around the same theme. I illustrate the themes with selected audio excerpts and descriptions, chosen for their representativeness of children's agency and for their correspondence with some of the major findings that emerged from the other schools visited by the NP3 research team.

\section{Findings}

I begin by describing the school's context and deployment of technologies more generally, followed by a close zoom on the agentic opportunities.

\section{Digital technologies and school ethos}

In comparison to other typical primary schools in the UK, the Northgate Primary had an atypically high amount and wide range of technologies available for their children. In each classroom there were eight iPads and an interactive whiteboard. Each classroom had the possibility to use a bank of notebooks, coding Bee Bots, stopwatches, visualisers or digital cameras. In the pre-school classroom, children had also access to a wall-mounted large touchscreen and a music system with loudspeakers. It was clear from the interviews with the teachers and senior leadership team that they were keen to make the best use of the technology resources. In particular, the teachers planned daily activities with attention to the different technologies they had at their disposal and often discussed the ways in which specific technologies might support children's specific skills. There was also evidence that conscious effort was made by the school to ensure that all children could access the technologies. For instance, there were several booster seats and comfortable cushions available for each classroom to enable children to sit comfortably regardless of their size or height. In addition to technology support, children were offered 1-to-1 support by a Teaching Assistant when they struggled with a certain program or app. The school had a floating ICT coordinator, who regularly responded to children's and teachers' queries and troubleshoots ICT-related problems. Teachers regularly set up homework that included a digital component, such as for example encouraging children to complete a part of an online activity at home or to produce a PowerPoint slide show to summarise children's understanding of a topic. Children who did not have technologies at home were encouraged to use the laptops and PCs available in the school. 
The senior leadership team had detailed knowledge about new technology developments and told me about their strategic investment in new devices. For example, during one of the interviews, the Deputy Head mentioned she would like to use part of the ICT budget to purchase new visualisers to show children artefacts in 3D. The teachers I spoke to engaged in regular coding-related activities in all year groups, but especially in Year 6. Additional activities were offered to children outside the school hours, such as for example the Coding Club on Monday or a course in touch-typing skills. The school used technology to communicate with parents and share children's achievements via social media. The school had its own Twitter account and a blog page, with regular contributions from children in Year 6. This whole-school approach to active and constructive use of technologies corresponded to some agentic engagements with technology by the individual children.

\section{Personalised learning with digital technologies}

The interviews with the deputy head teacher and members of the teaching team contained several examples of the school's aim to nurture each child's unique profile - a hallmark feature of personalised education.

Deputy Head:

'So in school our approach is not just you come in, you sit down and you learn. It's are you ready to learn? You know, are you okay? Are you in the right frame of mind? Do you need to take ten minutes in the reading area to just relax and read a book? And then I'll come over to you, when you are ready. And one of our main things is that our school's strap-line is that every child is unique. And it, it isn't a cliché really. It really is true. '

Teacher in pre-school:

'I mean, normally we take inspiration from the children's interest first, so we have got an awful lot of boys in school which is why we've got the cars, the electronic cars and why, you know, we've been reading about owls, so we've been finding out about they eat, so we've been cooking worms for snacks. So, trying to inspire the boys' inspiration really and imagination. Take it from the children all the time, what are their interests, what do they enjoy doing? And try and work on that. And what are their gaps in learning really as well.'

\section{Children's agency in technology use}

\section{Active and self-paced learning}

To identify and analyse children's agency in technology use, I focus on a specific lesson that I observed in the Year 6 classroom. This was a Maths lesson and focused on practising fractions in five different activities that were supported with five different resources at five tables. At Table 1, children could write their reasoning directly on the table surface and wipe it off if they made a mistake. At Table 2, children worked in pairs with Domino pieces and a stopwatch to measure the time it took them to solve each Domino challenge. At Table 3, the 
children solved various Maths scenarios individually and wrote their responses in pencil on a worksheet. At Table 4, the children used iPads with a pre-loaded Maths app. Table 5 was dedicated to the use of netbooks, which were preloaded with the school's online Maths learning software. Each activity was thus supported with a set of different resources, related to the practice of different Maths tasks and skills. Each activity included a competition element and a different support mechanism (human- or technology- mediated). It thus provided opportunities for children to gauge their knowledge against their peers (table1 andtable2), a software program (table4 and table5) or their own knowledge without any support (table3 and the worksheet). Such a pedagogical set-up reflects the pluralisation values of diversity and collaboration.

In terms of personalisation and markers of agency, the individual activities were set up by the teacher, and children did not have a choice in deciding which activity they wanted to take part in. The teacher carefully measured the time to ensure that all children spent an equal amount of time at each table. However, children were given ample opportunities to analyse a set of mathematical problems and discover the answers by themselves. Each child had access to one resource (digital or non-digital) at a time and apart from Table 2, which was set up for work in pairs, children could self-pace their own progress. The learning was thus personalised to each student, within the constraints of a typical classroom setting characterised by groups of children and restricted time for each activity.

\section{Self-directed learning}

Children's agency did not happen automatically; rather, there was a set of rules and behaviours embedded in the classroom culture that facilitated children's agentic engagement. For instance, children's independent use of notebooks and iPads was facilitated by a rotating group of students and digital ambassadors, who helped as and when needed. In addition to the classroom rules, I noted instances of agentic use of technologies at the school level. These were partly included in my observations as well as in the interviews with the senior leadership team. For instance, the school actively promoted children's use of the school's social media account, which was an email service similar to a synchronous chat with which children could send short messages to each other as well as their teachers. At the end of the lesson the teachers encouraged the children to edit their individual profiles on the school secure internal web server to suit their aesthetic preferences and share them with their classmates. The children were provided with log-in details and were repeatedly reminded to keep their passwords safe, so that they could access their online profiles anytime they wished.

\section{Awareness enabling choice}

These technology-related activities mirrored children's agentic engagement in other school activities. For instance, the school had a Pupils School Council, a group of pupils elected by their fellow pupils to represent their opinions. For Golden Time activities (activities at the end of the school day), children could choose their own activities, with any resources available in the classroom. Children were very aware of the opportunities given to them and there was a noticeable sense of pride in their verbal descriptions of the school's policies. 
Individual interviews with the case study children also indicated that there have been frequent conversations with the ICT coordinator about e-safety. For example, all children were familiar with restrictions for Facebook or Instagram use. This extract is from a focus group interview with Y6 pupils, in which we discussed the school's learning platform and communication server:

I: $\quad$ Okay, do you have passwords for other computers and other devices that you are using?

R: $\quad$ Yes, I have a lot of passwords.

I: $\quad$ A lot of passwords.

R: $\quad$ Yes, because in school, it isn't just you put a password onto your computer and you can log onto everything, because you have this, our own platform called Learn Anywhere and it's like you can talk to your friends from school and have picture and things.

R1: $\quad$ Messages and things.

R2: It's basically like mini like child friendly Facebook.

R: Like child's WhatsApp?

R2: Like say if you went on Facebook there's random people, you can only find your friends on it.

R1: And you can't get any other school's people on it, it's only your school and it's safe and if someone like messages you [inaudible 05:56] Miss Z [school's ICT coordinator] to help.

R2: You can say if you press it, someone has not sent you a very nice picture or email it flags it straight up to Miss $\mathrm{Z}$ and it sends her an email and she finds out what's going on.

R: Even if you don't flag it up, or an inappropriate word in it then it automatically it flags straight up to Miss Z.

R1: Even if you don't.

\section{Restrictions of agency}

The interviews with the log-children also revealed an opposite trend in relation to agency and technology use. There seemed to be significant restrictions concerning children's use of technologies at home. The restrictions were content- as well as time- and device-related. For example, child6 revealed that at home she only has access to apps that are free.

Ch6: Yeah, I type it into other the apple app store or Kindle's games store. And then I get the app, if I find anything suitable.

$\mathrm{R}$ What if it's a paid game?

Ch6: If it's a paid game, then I just don't get it.

R: Okay, so you only get the free games? 
Ch6: Yeah. Pretty much.

Child2 revealed that she can't go online because she doesn't have full Internet access at home.

R: Do you ever go online, do you look for ideas there or not really?

Ch2: Not really. Because I don't have full internet access. I can't really, but.

$\mathrm{R}: \quad$ Would you like to have internet access?

$\mathrm{CH} 2$ : Yeah.

R: Or you prefer not to have it?

Ch2: I would like to have it.

R: You would like to have it.

$\mathrm{CH} 2$ : Because, yeah, I like looking at like pictures and like looking up stuff.

Child 3 recounted how she enjoyed playing a game with a social component where players need to follow other players. However, she was not allowed to use the Follow feature when playing the game at home.

$\mathrm{R}$ : Oh, so what would you say is your favourite game?

CH3: Well, I've, I think my favourite game is one where you've got like this, it's a bit American, but it's like you've got this mall, and you've got to look like, collect all the money from it and build stuff and, and you can have several floors, and you can visit other people's malls and follow people, except we don't follow people because it's a bit dangerous.

As children talked about these restrictions they articulated the reasons for why they were not allowed to use particular programs or features. It was apparent that the rules and restrictions were imposed by their parents and that often there didn't seem to be a consistent or logical rationale. For example, child4 was told he can't access the YouTube channel but he was allowed to use free Google search, as shown in this extract:

R: Okay, okay. Do you ever go on YouTube to look for different things as well or?

Ch4: Sometimes but my dad doesn't really like me using YouTube because obviously there could be somebody using it that are very inappropriate

R: Right, right, so Google is okay but not YouTube? 
Ch4: Yeah

There were restrictions related to devices too. For instance, child 1 made it clear that she was given a smartphone because her parents wanted her to use the smartphone. There was little enthusiasm apparent on the child's part for using the phone for her own purposes.

CH1: My mum got me I think mainly because she just wouldn't want me not to, because she really doesn't even like being away from me for the weekend so, she asks for a certain number of texts. I don't know why, she just does. She probably bought it so I can text her.

The fact that smartphones are used by children to comply with their parents' monitoring preferences was also evident in child5's response. It was striking to note that the child has developed different communication strategies for different family members.

R: $\quad$ So is it a smart phone, that you can access different things with it?

Ch5: It's an iPhone that I use. I like take it the school as because I walk to and from school so like I use it to tell my parents like when I'm at school and when I'm leaving the house and when I'm back home and things

$\mathrm{R}$ Do you call them or do you text them?

Ch5: Sometimes I'll ring and sometimes I'll just send a message because I have a group with both my parents on

R: Okay

Ch5: So like I can send them text messages so they both see

$\mathrm{R}: \quad$ So is it through WhatsApp or?

Ch5: Through iMessage

Drawing on the interviews with the children, it was clear that they make distinct choices based on the technologies they have at home and they have at school. Moreover, when given the choice, they were discerning about which resource to use for which purpose, as illustrated in this extract about the child5's preference for digital books.

R: $\quad$ So do you listen to your music before you go to bed or?

Child5: Yeah, I normally go sit in bed for a bit listen to music and then I'll put, switch everything off and then read for a bit, and then go to bed.

Child5: Do you read on your iPad? Or do you read?

Child5: $\quad$ Real books.

R: $\quad$ Real books? 
Child5: $\quad$ Yeah.

$\mathrm{R}$ : Why is that?

Child5: I think it's more, I just like reading actual books instead of using devices for reading. I think it's a bit better.

$(\ldots)$

Or my mum will use her Kindle.

R: $\quad$ But you for reading you prefer the real books?

Child5: $\quad$ Yeah, I prefer real books otherwise it's just, I don't know why but I just like it.

R: That's interesting. I mean you are reading a real book now, right, so. Is it because that you can feel the book or?

Child5: $\quad$ Yeah, I like being able to actually look at the front cover and everything, and read the blurb, whereas if you have it on a Kindle you can't really read the blurb or anything, its straight into the book. I just.

R: Yeah, that's a good point.

Child5: I got a Kindle once, but I didn't really like it as much as reading real books, so I just went to back to reading books. I just prefer it.

\section{Discussion}

The rules around technology use for young children are decided by their teachers and parents, who can either enable or restrict children's agency and personalised learning. For the children in the Northgate school there was a disconnect in children's accounts in relation to what they could do with mobile technologies at school or at home. In the school, the children had a set of options and they all had equal opportunity to try one of the options, such as for example one of the five activities mediated by technologies in the Maths lesson. The children could not choose which particular app or device to access on the device, but when personalising their online avatars, they could choose any picture they wanted and message their friends any content they wished, as long as it complied with the school's rules. Each child needed to comply with the same set of rules but within them, they were free to personalise their own learning. Such an approach is in alignment with the personalised pluralisation agenda. Yet, when using the technologies at home, the rules were decided by the individual parents and they varied from family to family. Many of the rules were content-related, restricting personalisation. The purpose of using technology at school was to enrich children's learning or communication with each other. The purpose of using technology at home was more diverse and often oriented towards adults', rather than the children's, interests. While in the school there was an adult physically present all the time, at home, adults were present at distance, via the technology used by the child. 
The first three themes of the analysis - Active and self-paced learning; Self-directed learning and; Awareness enabling choice - were all related to children's use of technologies in the school. There was evidence of personalised learning happening in the Maths lesson that I observed. There was a restricted time for each activity within the Maths lesson but each child had equal opportunity to achieve as much as they could within this restricted timeframe. This is different from classrooms led by standardised curriculum based on large groups where highest achieving students need to wait for the low achievers who struggle.

In contrast, the theme Restrictions of agency came up strongly when children described their use of technologies at home. It might be that children were more negative about their experiences at home because the interviews took place in the school, thus giving them some distance from home, possibly facilitating more open and critical answers. Yet, all log children were interviewed 1-to-1 with the researcher, without the teacher's presence. In addition, the interviews were facilitated with pictures of technology used by home, which were taken by the children themselves and featured a range of technologies available to them at home. It is possible that children expect to be agentive at home and therefore note when they are prevented from being so more than they do when in school. Overall, however, the many restrictions listed by children in relation to their use of technologies at home seemed to indicate that the school supports more agentic engagement than children's parents at home. This is not a typical finding; indeed, in another school that participated in the NP3 study, the opposite was the case. In the Northgate school, children's volitional, independent and autonomous use of technology was noticeable in children's learning activities, as well as their attitudes towards technology use in the school.

This finding conveniently skirts the question of what does personalised learning look like and what its impact on children's experiences might be. To answer this question we need to go beyond the immediately obvious markers such as access or availability of technology. The "Cs" framework reminds us that the context, content and the individual children's experiences matter. For the Northgate children, the access and availability of technology were not an issue neither at home nor at school. It was the opportunities mediated by the teachers and parents that influenced children's agentic use of the technology available to them.

\section{Supporting children's agentic use of technologies}

When we consider Northgate children's perceptions about the usefulness of digital versus print books, it seems that they were discerning about the purpose and added value of specific technologies. To develop this level of understanding, however, they needed to be old enough to explore and understand the features of the technologies. Different contexts of technology use (e.g. reading digital books) provide different learning opportunities. For child5, there was a clear difference between reading on Kindle or on paper. Research with simple digital books (e-books) shows that children use them to read for information, escape, review of knowledge and study (Schcolnik, 2001). Individuals differ in how they process information from texts to derive meaning from them (Linderholm \& van den Broek, 2002), and some text genres might be more associated with one reading purpose than others (Best, Rowe, Ozuru, McNamara, 2005). However, there is an almost universal agreement in the reading literature that books 
are important for children's learning and the role of digital books in children's reading diet must be better understood (e.g., Kucirkova, Snow, Grover \& McBride, 2017). Granting children more agency in choosing the appropriate reading format, as evidenced at home for Child5, would be more in alignment with the participatory model of personalised learning.

\section{Asking the right questions}

From Bernstein and Leaton-Gray's (2017) perspectives, the time children spend using technology at home counts as part of their learning but their personal agency becomes constrained if, as it was the case with the Northgate children, technology is allowed only for monitoring or playing free and limited-feature apps. In their recent book, Leaton-Gray and Phippen (2017) discuss how adults' understanding of children's risk undermines, if not erodes, children's rights and free identities. The potential for home-school connected learning afforded by mobile technologies was not realised for the Y6 children. Interestingly, as we discuss in Gillen and Kucirkova (forthcoming), for the early years classrooms there were noticeable trajectories in children's technology use and signs of flow between home and school. It is essential that researchers search for detailed counter-examples, such as the ones presented here, to think more deeply about children's actual experiences with digital technologies at home and in school.

\section{Conclusion}

Personalised learning with digital technologies appears in several guises and this chapter has illustrated primary school children's (non)agentic engagement with mobile technologies in the classroom and at home. With mobile technologies such as tablets and smartphones, children's learning engagement could travel between home and school - so long as the adults who mediate the technology use in these spaces create opportunities rather than barriers for children's agency. Although on the surface level, children might have access to many devices, it is the agency they are afforded in their use that influences their learning experiences. I therefore conclude that the potential of mobile technologies to support personalised pluralisation can be realised, but only if we address the attitudes of all adults mediating children's learning in schools and at home. 


\section{References}

Bélanger, J., \& Broeks, M. (2016). Attracting and Retaining Teachers in Cambridgeshire: Working Conditions and Teachers Flows from a School Workforce Census Data Perspective. RAND Europe.

Best, R. M., Rowe, M., Ozuru, Y., \& McNamara, D. S. (2005). Deep-level comprehension of science texts: The role of the reader and the text. Topics in Language Disorders, 25(1), 65-83.

Blum-Ross, A. and S. Livingstone (2016) Families and screen time: Current advice and emerging research. Media Policy Brief 17. London: Media Policy Project, London School of Economics and Political Science.

Eisen, S., \& Lillard, A. S. (2017). Young children's thinking about touchscreens versus other media in the US. Journal of Children and Media, 11(2), 167-179.

Garrick, B., Pendergast, D., \& Geelan, D. (2017). Personalised or Programmed? Current Practices of University Systems. In Theorising Personalised Education (pp. 83-93). Springer Singapore.

Golinkoff, R. M., \& Hirsh-Pasek, K. (2016). Becoming brilliant: What science tells us about raising successful children. New York: American Psychological Association.

Guernsey, L. (2012). Screen time: How Electronic Media from Baby Videos to Educational Software Affects Your Young Child. Hachette UK.

Hempel-Jorgensen, A. (2015). Learner agency and social justice: what can creative pedagogy contribute to socially just pedagogies?. Pedagogy, Culture \& Society, 23(4), 531554.

Johnson, L., Adams Becker, S., Estrada, V., \& Freeman, A. (2015). The NMC Horizon Report: 2015 Museum Edition. New Media Consortium. 6101 West Courtyard Drive Building One Suite 100, Austin, TX 78730.

Kraemer, K. L., Dedrick, J., \& Sharma, P. (2009). One laptop per child: vision vs. reality. Communications of the ACM, 52(6), 66-73.

Kucirkova, N., \& Littleton, K. (2016). The digital reading habits of children: A national survey of parents' perceptions of and practices in relation to children's reading for pleasure with print and digital books. London: Book Trust.

Kucirkova, N., \& Littleton, K. (2017). Developing personalised education for personal mobile technologies with the pluralisation agenda. Oxford Review of Education, 113.

Kucirkova, N. (2015). The Cs in Children's Screen Time: Some Food for Thought, Huffington Post, Available online from: http://www.huffingtonpost.co.uk/dr-nataliakucirkova/the-cs-in-childrens-screen-time_b_8034994.html 
Kucirkova \& Gattis (in preparation)

Kucirkova \& Gillen (forthcoming) Rivers that flow both ways: creative ways of using digital technologies to connect children's school and home lives, British Journal of Educational Technology

Kucirkova, N. (submitted) Against the myth of digital childhoods, In Montgomery, H. \& Robb, M. (eds) (2018) Children and young people's worlds, Open University Press.

Kunz, A. H., \& Pfaff, D. (2002). Agency theory, performance evaluation, and the hypothetical construct of intrinsic motivation. Accounting, organizations and society, 27(3), 275-295.

Leaton Gray, S. (2017). The social construction of time in contemporary education: implications for technology, equality and Bernstein's 'conditions for democracy'. British Journal of Sociology of Education, 38(1), 60-71.

Leaton Gray, S., Phippen, A. (2017). Invisibly blighted: the digital erosion of childhood. UCL IOE Press: London.

Linderholm, T., \& van den Broek, P. (2002). The effects of reading purpose and working memory capacity on the processing of expository text. Journal of Educational Psychology, 94, 778-784.

Lupton, R., \& Hempel-Jorgensen, A. (2012). The importance of teaching: Pedagogical constraints and possibilities in working-class schools. Journal of education policy, 27(5), 601-620.

Mercer, N., Hennessy, S., \& Warwick, P. (2010). Using interactive whiteboards to orchestrate classroom dialogue. Technology, Pedagogy and Education, 19(2), 195209.

Ofcom (2015) Children and Parents: Media Use and Attitudes Report, Available online from: https://www.ofcom.org.uk/research-and-data/media-literacyresearch/childrens/children-parents-nov-15

Ofcom (2016) Children and Parents: Media Use and Attitudes Report, Available online from: https://www.ofcom.org.uk/research-and-data/media-literacyresearch/childrens/children-parents-nov16

Papadakis, S., Kalogiannakis, M., \& Zaranis, N. (2018). Educational apps from the Android Google Play for Greek preschoolers: A systematic review. Computers \& Education, 116, 139-160.

Prensky, M. (2001). Digital natives, digital immigrants part 1. On the horizon, 9(5), 1-6. 
Schcolnik, M. (2001). A study of reading with dedicated e-readers (pp. 1-145). Nova Southeastern University.

Shapiro, S. P. (2005). Agency theory. Annual review of sociology, 31.

Sharples, M., Adams, A., Alozie, N., Ferguson, R., FitzGerald, E., Gaved, M., ... \& Roschelle, J. (2015). Innovating pedagogy 2015: open university innovation report 4.

Selwyn, N. (2016). Is technology good for education?. New York: John Wiley \& Sons.

Travis, M. A. (1998). Reading cultures: The construction of readers in the twentieth century. SIU Press.

Twining, P., Browne, N., Murphy, P., Hempel-Jorgensen, A., Harrison, S.

\& Parmar, N. (2017). NP3 - New Purposes, New Practices, New Pedagogy: Meta-analysis report. London: Society for Educational Studies. http://www.np3.org.uk (accessed 13-Nov-

2017)

Vaala, S., Ly, A., \& Levine, M. H. (2015). Getting a Read on the App Stores: A Market Scan and Analysis of Children's Literacy Apps. Full Report. In Joan Ganz Cooney Center at Sesame Workshop. Joan Ganz Cooney Center at Sesame Workshop. 1900 Broadway, New York, NY 10023.

van Dijk, E. M., Lingnau, A., \& Kockelkorn, H. (2012, October). Measuring enjoyment of an interactive museum experience. In Proceedings of the 14th ACM international conference on multimodal interaction (pp. 249-256). ACM. 